\title{
Virtual Project Management: Examining The Roles And Functions Of Online Instructors In Creating Learning Applications With Value
}

Bob Barrett, American Public University, USA

\begin{abstract}
While many students and instructors are transitioning from the brick-and-mortar classrooms to virtual classrooms, labs, and simulations, this requires a higher-level of expertise, control, and perseverance by the instructor. Traditional methods of teaching, leading, managing, and organizing learn activities has changed in terms of the virtual learning environment with regard to the use of technology and how learning can be delivered virtually. What does this mean for instructors as more and more colleges and universities are now competing for students, as well as maintaining a required level of academic quality and standards? This paper will focus on the roles, functions, and multi-tasking skills of online instructors in order to be successful in meeting the academic, virtual, and career needs of their adult learners. This paper will demonstrate how one online program is redesigning their global management coursework to help accomplish the above stated needs and invigorate their course with more "hands on" application and student involvement. In the current global management course, the students learn about current issues facing companies working in other overseas locations or learning about other companies considering the possibility of becoming global. While many educators will agree that learning concepts, principles, and theories are necessary in establishing a good foundation of learning in any course, this may not be enough. While instructors may have a challenging position of motivating and keeping the attention of young learners, we can also see the same problem with adult learners. Equally important to note here is the challenges that online instructors may have in motivating and keeping the attention of virtual learners when there are issues of differences in generational learning, time zone challenges, technology skills, and perceptions of course value. Therefore, instructors for this course took another look at the current assignments and final project and realized a change in design and presentation could make a difference.
\end{abstract}

Keywords: Virtual Management; Virtual Learning; Online Learning; Learning Applications

\section{INTRODUCTION}

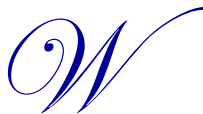

hile technology evolves in today's world, so does the skills and abilities of the current and future workforces. Harris (2000) suggested that the "new workplace requires a new type of employee, one who is highly skilled, flexible, creative, and attuned to working as a member of a team" (p. 1). Therefore, how can we prepare our instructors to become one of these new types of employees? This is the perspective of today's university trainers and academic administrators, but also instructors are realizing the need to change their viewpoints and how they can best prepare for life in the virtual classroom. Teaching in the virtual learning environment is not a clear-cut set of instructions, there is a greater need for instructors to perform more functions, assume more roles, and be available more often than their counterparts teaching in brick-and-mortar classrooms. While many instructors are aware of the technological needs of their changing profession, they also realize that there are other roles in which they need to perform and maintain in order to meet the various learning need. 
In 2012, the U. S. Department of Education stated that the following changes needed to be done.

Workplace education programs focus on the literacy and basic skills training workers need to gain new employment, retain present jobs, advance in their career, or increase productivity. Curricula are developed by educators, working with employers and employee groups, who assemble written materials used on the job and who analyze specific jobs to determine what reading, computation, speaking and reasoning skills are required to perform job tasks effectively. By their nature, successful efforts to institute workplace literacy programs require strong partnerships among educators, employers, and employees. (Fact Sheet 16)

Further, the WEA and AFT Taskforce Report (2005) noted that "Part-time instructors bring unique skills and expertise into workforce preparation and academic classrooms. Employing part-time instructors allows colleges to offer more classes, when and where students need them and the ability to respond to emerging student, community and business needs. However, low salary levels, variable working conditions and over-reliance on part-time faculty have contributed to staffing concerns in Washington State and nationally - as colleges and universities absorb greater numbers of students without appropriate funding" (p. 1). Whereas, several educational institutions tried to address the issue of obtaining the best possible candidate for these online positions, they have not always been as competitive in pay or benefits. As we can see the role of the instructor, especially the online instructor has been changing. Later in this paper, there will be a discussion as to how this "new type" of online instructor can make a difference in the learning applications for today's adult learner. Why is this so important? As we know adult learners have their own unique learning style, and an instructors can see multiple needs for the various learning styles in today's classroom.

\section{CHANGING ROLES OF THE ONLINE INSTRUCTOR}

There is no one role for instructors today - especially in the virtual learning environment. The online instructor may be a facilitator, creator, manager, organizer or career coach at any time. Many online students are working adults who try to juggle work, school, and personal lives. This is not an easy task, and equally important, their instructors face the same challenges. Thus, online instructors need to understand the mindset of their learners and what they are seeking to accomplish in their academic endeavors. In this regard, they need to be creators of a dynamic learning environment and provide creative, yet innovative ways to encourage, motivate, and sustain the learning endeavors of today's virtual students. While this set of processes is in motion, the virtual instructor needs to manage and organize the learning processes from start to finish. In addition, to each of these roles, the final and perhaps most demanding role of is that of a career coach. While considering each of these roles, we need to explore the key functions of online instructors. While they are required to achieve certain prescribed learning objectives for each course, as well as connect their course with the overall program of study, they need to bring value to the online learning environment. Let us take a moment and look at the recruiting and hiring methods used in the past and now for the future to determine if there are changes. If so, are these changes helping to select the quality of online instructor that can help educational institutions to move forward?

\section{WHAT IS THE TYPICAL CHARACTERISTICS OF TODAY'S ONLINE INSTRUCTOR?}

According to Roueche, Roueche, and Milliron (1995) stated, “Adjunct faculty are increasingly important players in the teaching and learning process. It is in the college's best interest of appreciating the investment value of them, and ultimately in the interest of establishing and maintaining the college's reputation for teaching excellence" (p. 120). As noted early, many online teaching positions are being filled by part-time instructors. Many colleges and universities have found that this helps to reduce some administration of benefits and pay - so part-time faculty have been a "quick fix" for their current need. However, it should be noted for the purposes of this paper that there may be a change in this situation within the next decade or two as more part-time faculty seek more pay and benefits (i.e., union organization). As more educational institutions are realizing the need for changes in the types of instructors for the classroom, they have also realized the need to change their recruiting and hiring methods. 


\section{CHANGING RECRUITING AND HIRING METHODS - ADJUSTMENT OR NOT?}

Over the past two decades, universities have recruited and hired online instructors based on their own review of received resumes, as well as recommendations by others. Nonetheless, these methods may not be efficient enough to accommodate the needs of educational institutions in staffing their online teaching positions. As a result, many of these institutions are searching for better methods of recruiting and hiring personnel. While some have outsourced these human resources duties, other schools are learning how to create and implement best practices in order to seek, interview, hire, and train potential online instructors to teach their online course offerings. According to Jones (1993) described best practices as centered:

on the very essence of good management: guiding employees toward greater productivity, liberating them from the burdens of disorganization without saddling them with restrictive bureaucracy, and helping them to overcome some measure of the troublesome flaws inherent in people and processes. These are the measures of effectiveness and efficiency (p. 11).

This leads to yet another question to consider in our paper - how can we improve upon our current recruitment and hiring practices? Further, as more educational institutions are beginning to offer more courses online, there is a need for a different type of educator/facilitator. While technology, as it has been stated earlier in this paper, has played a major role in the transformation of how learning can be offered, the learning has to be facilitated and monitored by well-skilled and articulate individuals. These online educators need to offer highquality learning, but in a different educational format. Thus, these instructors need to possess additional skills and characteristics that will "fit" both the needs of the online learner, as well as the educational institution.

While more and more post-secondary Human Resources (HR) departments still recruit, interview, and hire personnel according to antiquated methods used for face-to-face interaction, best practices in industry have been called for change. The use of technology has once again helped many schools in changing their current practices to develop yet newer and improved ones. When one needs to recruit for virtual positions, the ability to personally meet and interact with candidates on a one-on-one basis may not always be possible. Thus, there is a need to change this outdated recruiting and hiring methods and procedures in order to meet the changing needs of online course offerings. The role and function of online faculty is to teach students in online environment utilizing online educational software, as well as providing a quality education. As a result, there is a growing need to develop and implement better recruiting and hiring processes to accomplish such change in the current HR paradigm. During the first part of this paper, a framework has been building in the various discussion points of the role of technology and how it has impacted not only education in general, but also the facilitators of education. Along this same line of thinking, the changing roles of skills sets of instructors has now play a growing impact on how learning is offered, implemented, and evaluation. As a result, this second part of the paper will focus on how the whole "way of learning" and "course offerings" are evolving and become more technologically friendly, as well was encouraging learners to see more educational opportunities. Thus, this helps to motivate today's adult learner, as well as help them see more applicability of their studies in today's workplace and their own personal lives.

\section{TRADITIONAL HOMEWORK ASSIGNMENTS - CAN THEY SURVIVE IN THE ONLINE ENVIRONMENT?}

As more and more students are seeking additional education and training, they have specific learning needs and wants. In particular, they see value for their educational investment, as well as seeing how various courses fit into their program of study and their career endeavors. One way that instructors can accomplish the learning objectives, meet student learning needs, demonstrate value, and reach for higher academic standards is through the use of virtual projects. While many adult learners may equate "school work" or "homework" with previous learning experiences of their youth, instructors today need to "break away" from these "old paradigms of learning" and create new paradigms of learning and show values. Teaching adults learners greatly will differ from teach younger adults, in that adult learners have a stronger need for education and want to see value for their investment. Therefore, this leads to the central theme of this paper - how does online instructors create learning projects that meet learning objectives, motivate and encourage learner involvement on different levels, as well as causing their students to want to learn more and seek further knowledge and application of their content knowledge in their personal, academic, and professional lives. 
As technology is ever changing, the creativity and innovative ways of teaching must also continue to change. Instructors and course designers need to enhance and modify their online programs. In particular, this paper will address how one educational system redesigned their global management coursework to help accomplish the above stated needs and invigorate their course with more "hands on" application and student involvement. In the current global management course, the students learn about current issues facing companies working in other overseas locations or learning about other companies considering the possibility of becoming global. While many educators will agree that learning concepts, principles, and theories are necessary in establishing a good foundation of learning in any course, this may not be enough. While instructors may have a challenging position of motivating and keeping the attention of young learners, we can also see the same problem with adult learners. Equally important to note here is the challenges that online instructors may have in motivating and keeping the attention of virtual learners when there are issues of differences in generational learning, time zone challenges, technology skills, and perceptions of course value. Therefore, instructors for this course took another look at the current assignments and final project and realized a change in design and presentation could make a difference.

If we look at the various evolutionary steps of technology in today's learning environment, we can see how it has influenced the diminishing workforce, as well as the workplace in general. It has caused many human resource professionals to search for information and ideas on best practices in human capital management (Fitz-enz, 1997). As changes in technologies have occurred in the workplace, as well as changes in the various federal, state, and local laws, there has been a shift from these changes to human problems, especially behavioral ones see on the individual group, and organization levels. Chin and Benne (1969) discussed this shift to the human problems as "dealing with the resistance, anxieties, threats to morale, conflicts, disrupted interpersonal communications, and so on, which prospective changes in patterns of practice evoke in the people affected by the change" (p. 94). Therefore, those individuals involved in technological and human asset management work as "change agents" to help facilitate change in terms of best practices.

Further, Fitz-enz (1997) described best practices as: "an enduring commitment to a set of basic beliefs, traits, and operating stratagems. These are the guidelines for an organization: the driving forces that distinguish it from all others" (p. 98). Earlier in 1990, The Saratoga Institute conducted a formal research project on common traits of the best human asset management companies. The question that they used over and over with each participant was, "Who is good at _ ? ? The identified eight factors that appeared constantly in their study as: "1) value; 2) commitment; 3) culture; 4) communication; 5) partnering; 6) collaboration; 7) innovation and risk; and 8) competitive passion" (Fitz-enz, 1997, p. 100). They wanted to find out what was being done better in each of these factor areas. The study was to help them to identify what was being done right and if it was part of the individual's interaction with their organizational culture. While many people have researched and interviewed others to learn more about best practices, the educational arena has had to work even hard to develop, create, implement, and share best practices with others in order to help improve upon the current approach to online learning and teaching.

So we circle back to the original question posed in this section - can traditional homework (or learning in general) survive in the online environment? In order to fully appreciate this question, we have to look at why adult learners have returned or not returned back for further education. Many adult learners may desire never to return back to school if they can survive long enough to obtain a high school diploma or GED certificates. Why? Well, they be tired of "required learning" or they me exhausted of "trying to learn" in ways that are counterproductive to their own learning style. More and more studies have focused on the various learning styles of adult learners and why learning styles are quite important in today's learning environment (Kolb, 1984, 1999). As a result, today's instructors are faced not only with facilitate learning with those who have a genuine desire to learn, but they also must approach learning different with various new adult learners who "might want to give learning another try, but are still skeptical and afraid of failing with a new type of learning on a higher-level." Thus, this next section of the paper will focus on how one online instructor has taken a new approach to online learning to give more meaning to one's learning, as well as showing applicability of the new content knowledge, as well as enhancing one's current skills sets for today's ever-changing workplace. 


\section{MAKING A DIFFERENCE IN EDUCATION - VIRTUAL MODIFICATIONS AND ADAPTATIONS}

The key question posed by several instructors was whether the course' $\mathrm{s}$ assignments and project were linked together, perhaps in a sequential fashion to link learning concepts or perhaps designed to cover only certain learning objectives. In other words, they looked at the key point raised by several other instructors - how can we create a more dynamic course, capture more student attention and involvement, as well as showing how the course learning would be important to their professional career. Thus, they could see the need to link learning events/activities and help students see the need to become involved early in the course and work with a purpose not just for course credit - but with a drive to learn and know more about the course and how the course could help them for the future. Thus, this paper will outline how one online instructor has taken some general business courses and updated them with a technological and career development approach to help individual adult learners see the usefulness of their learning in the course, as well as how their final project can be helpful to them in the future. Besides, updating the learning approach, the instructor noted that it is important to know the change in learning behaviors and use of learning styles during this transformation in order to continuous upon the process - and to interact more with the students to show them that they do not need to "memorize" material in order to retain it. This definitely has been a selling point to those adult learners who were a bit hesitant in returning back for further education. Thus, this paper will help other instructors and administrators see how to take a current course, examine it with a new "paradigm approach to learning" and create more "energized" value-added courses to attract students in terms of wanting to learn and applying their learning to real world applications.

Now let us examine ways to enhance online courses with real world and captivating learning applications. The author of this paper wanted to change the way certain business courses were being offered online, and he was asked to design and develop two graduate-level courses that previously consisted of some basic written assignments (short papers) and various discussion questions. However, it was emphasized that this was the first time they would be offered online and their acceptance and use by the student body would be a key influencing factor as to whether there was going to be a viable need for online learning at the university. With this line of thinking in mind, the instructor took a quick look at the current syllabus and tried to "capture" the learning in a virtual plain, as well as envisioning what today's adult learning could derive from the course and whether it would be strong enough to help them retain the knowledge for future use.

One key underlying thought helped to frame the design of these courses - what could the adult learner use now and in the future? Could the content knowledge gained from these courses be useful in the future or was it good enough for the immediate need to complete the course and obtain course credit? The designer focused more on the immediate needs and future outcome/learning that could be useful in the future for the adult learner. The two courses examined here were Human Resource Development and Organizational Consulting.

In the field of Human Resource Development (HRD), there three key areas of focus: education, training and development, and career development. Thus, the instructor felt that the intended audience could benefit from doing one key project on training and development, rather than focus on a small set of written papers. Why not develop a project that could be "actually used" in today's workplace. In fact, in each course offer, there would be usually a few students who would already be working in the workplace that had an immediate need in their company for such a project. Therefore, this not only helped these students, but it also helped others to see applicable of their work early on in the development stage of their project. In essence, each student had to pick form a list of five (5) possible training scenarios to develop a fully-developed training project for at least a 3 - to 5-day period. They had to concentrate on the four states of training: 1) needs assessment; 2) design and development; 3) implementation; and 4) evaluation. During this course, the instructor held various live discussions, communicated regularly with students on the project and their project status, and assigned various parts of the training program to be completed (such as their own milestones to be discussed).

At first, some of the students were not too quick to buy in and show ownership, but as the course progressed and discussions continued, they soon realized that this project was indeed "their project." However, as they started to created and assemble their training project, they could see the current, if not future, use of the project as a possible interviewing artifact to show potential employers (but carrying a copy on a USB stick). Some of the key comments shared with the instructors did vary. While some thought it was a very detailed and arduous process, 
others were surprised at how it all "came together" and they had an actual work product to walk away with - rather than just turning in one-time use papers. Other students actually took the project with them on job interviews and discussed their MBA work and were surprised how quickly potential employers were interested in their studies and amazed at how school work has progressed over the years.

In another course, the author designed in the same fashion by examining the same course offered on Organizational Consulting, but with an emphasis on "immediate use." Originally, this course had a consulting group approach, rather than an individual perspective. The author did not like this approach and reacted with a change in design due to the changing economic outlook. Why take courses that forced "students" in learning to work only for others - why not learn how to work for yourself? Too many people have lost their jobs over the past two decades, and many of them "did not know" how to work for themselves as a change of pace. Thus, the instructor wanted a more "individualized" approach for this course and show each student how to frame and carve out their own consulting business and niche in today's highly competitive market.

So, how did this approach differ from others? Well, in many academic courses, course objectives help frame the course and course designers follow traditional forms of instructional systems design. However, there is no written rule that prevents the course designer from thinking "outside of the box" and thinking of future learning and work endeavors. As a result, this course needed not only a different approach, but it also was to be offered online and needed to be appealing and academically sound. Thus, the work began with the current course offering materials and assignments. While the instructor was told that the course's objectives could not be changed, the course could be adapted with other components in order to achieve all course objectives. Thus, the designer had to think of how to create a course to meet not only the course objectives, but also add a fresh new approach to the content knowledge, as well as motivate the learner to want to consider the possibility of consulting a potential career endeavor.

The course began with early discussions with the students and instructors to pose the first main question so do you think you are smart enough to be your own boss? This was followed by another question for consideration - why work for others when you have skills and experience to work for yourself? Not all students are "risk takers" and some will find comfort in many places. However, the instructor realized that why many adult learners are not risk takers is simple - they cannot simply afford to take risks and lose. However, when they could see an earning potential, especially on a part-time basis and with low overhead costs, they started to participate more in the course. In fact, the instructor took the course content as the basic learning blocks to demonstrate to them how they could create a part-time consulting business on their own by doing their own research. They were required to think of a potential consulting business and to investigate how to incorporate in their own area. Also, they had to think of a company name and develop their own marketing materials in terms of an electronic brochure and webpage. Also, they created a sample SWOT analysis to share with potential clients. Now, how did this help students see the bigger picture?

Well, the instructor realized that there would be students who would to the work by piece by piece and not see connections. This is where the instructor had to invest in more teaching in terms helping all students see how each piece of their Electronic Consulting Plan (ECP) was important. This ECP could serve an interviewing artifact to show potential employers as to what they did in their studies. Also, this ECP was a living document, one that could be added to and modified according to their current and future needs. In fact, a few students actually pursued the area of consulting and opened their own consulting business. As noted in the previous discussion on the training program, some of the students were surprised at how much they learned during the term and being able to walk away with a work product for their use. Many students noted that they would do "busy work" for other courses, but this type of work was not only busy in terms of time, but more applicable to their own learning needs and future career decisions. The key here was the use of technology helped to reinforce the learning for the students, enabled the instructor to be able to communicated more in real time, as well as allowed the students to see more readily their virtual documents and applicability (as well as how the Internet could be used a key vehicle for promotion of their consulting business endeavors). 


\section{CONCLUSION}

Project management has changed drastically over the past few decades with the changes of technology, both in the workplace and education. Online instructors have to keep up to date with the many changes of technology, as well as facilitating learning according to the various types of learning styles with today's adult learners. In particular, today's learner needs to see utility and value in their learning, as well as a change in how learning is offered and measured in today's online learning environment. As covered in this paper, the roles and functions of online instructors are ever changing, and today's instructor needs to change his or her approach to learning. The movement away from teacher-centered approach to learning has evolved to that of a student-centered approach. Students want to have more ownership in their learning. As a result, this particular paper has addressed how one online instructor has taken the general learning approach to two business courses and added in more technology, as well as a career development perspective, to help students gain more ownership of their learning and see more value in their educational endeavors.

\section{AUTHOR INFORMATION}

Dr. Bob Barrett is a professor in the School of Business at the American Public University. Dr. Barrett's current research interests are: Online Learning, Intellectual Capital, Human Resource Development (HRD); Human Resource Management (HRM); Virtual Management Teams; Disability in the Workplace. He speaks both nationally and internationally on these topics, with an emphasis on online learning, disabilities, and intellectual capital/knowledge management. Dr. Barrett currently teaches and writes on the subject of global business in today's changing economic times. E-mail: docjob00@msn.com

\section{REFERENCES}

1. Chin, R., \& Benne, K.D. (1969). General strategies for effecting changes in human systems. In W.G. Bennis (1969). The planning of change. New York, NY: Holt, Rinehart and Winston.

2. Harris, H. (2000). Defining the future or reliving the past? Unions, employers, and the challenge of workplace learning. Columbus, OH: ERIC Clearinghouse on Adult, Career, and Vocational Education, Information Series, No. 380.

3. Fitz-enz, J. (1997). The truth about best practices: What they are and how to apply them. Human resource management, 36(1), 97-103.

4. Kolb D. (1984). Experiential learning: experience as the source of learning and development. Englewood Cliffs, New Jersey: Prentice Hall.

5. $\quad$ Kolb D. (1999). The Kolb Learning Style Inventory, Version 3. Boston: Hay Group.

6. Jones, T.L. (1993). The Americans with disabilities act: A review of best practices. New York: AMA.

7. Roueche, J.E., Roueche, S.D., and Milliron, M.D. (1995). Strangers in their own land: Parts-time faculty in American's community colleges. Washington D.C.: Community College Press.

8. U.S. Department of Education (March 2000). Fact Sheet 16. Washington, DC: Division of Adult Education and Literacy, Office of Vocational and Adult Education, USDE.

9. Washington Education Association and American Federation of Teachers - Washington (Nov. 21, 2005). Best employment practices for part-time faculty. Taskforce report and recommendations. Retrieved 1/26/09 from http://www.sbctc.ctc.edu/college/ hr bestpractices.aspx. 
NOTES 